\title{
Unintended consequences of community-based monitoring systems: Lessons from an HIV prevention intervention for sex workers in South India
}

\section{INTRODUCTION}

The turn in development towards community-driven and participatory programming has led to a simultaneous effort to institute monitoring systems that are also community-based (Estrella and Gaventa 1998). Such an approach to monitoring has been embraced because of its potential to decentralize governance, improve accountability, lead to evidence-based planning and empower communities to take ownership of development projects, thereby improving desired program outcomes (Bill \& Melinda Gates Foundation 2013; Mansuri and Rao 2012). Studies have examined whether community-based monitoring leads to increased accountability of public officials (Afridi 2008), better service delivery (Bjorkman and Svensson 2009) and social change (Van Risjoort and Jinfeng 2005). However, the literature is scant on the monitoring process itself, i.e., the challenges of quantifying complex social phenomena, how various actors (NGOs or the 'community') perceive the monitoring systems or the consequences that derive from the monitoring process.

This paper fills the gap in the literature using ethnographic data on the community-based monitoring systems designed for, and implemented by, female sex workers (FSWs) affiliated with an HIV prevention NGO in Andhra Pradesh, India. The data are drawn from Project Parivartan, a mixed methods study whose research objective was to understand both the process and the impact of the NGO's implementation. As a purely research organization, Parivartan was separate from, and independent of, the NGO and had no implementation responsibilities. This paper uses a sub-set of the ethnographic data that is relevant to the 
conceptualization and implementation of the community-based monitoring tool called the "SCA Visual Diary" (henceforth "Visual Diary). The paper's aim is to show how, despite the best intentions of an NGO committed to the goals of community participation and ownership, the pressure to quantify complex social interactions had the unintended consequence of undermining the key original community-based objectives of the intervention.

The overall goal of the NGO was to implement an intervention that mobilized and empowered FSWs to eventually take charge of the prevention intervention. The NGO viewed the Visual Diary as a tool to provide FSW input on the intervention, refine intervention strategies and enable FSW participation in decision-making. Inspired by the theoretical underpinnings of participatory development, the NGO spent considerable thought and effort to create monitoring tools that accomplished these goals which were also tailored for a largely non-literate population. As stated in an NGO document, "What is innovative here is that the monitoring is conducted by the community members themselves." (Care-Saksham Booklet, undated, Page 17).

This paper focuses on the monitoring of two activities that were critical to intervention goals: condom distribution and condom needs assessment. We show that the Visual Diary's fixed system of counting condom-related activities did not account for the variability and mobility of sex work practices and ignored the FSW community's existing counting strategies that were based on an intimate knowledge of the local sex trade. By devaluing FSW voices, the NGO undermined its own goals of implementing a 'community-led' intervention. In the process, monitoring became an imposition for both the FSWs and the local NGO staff, thereby thwarting the radical spirit with which monitoring was originally conceived. 
The analysis for this paper builds on a vast literature on the social and political consequences of the processes of quantification. The generation of numbers, and the knowledge it creates, is not neutral nor is its impact uniform across time and space (Appadurai 1993; Cohn 1984; Espeland and Stevens 2008; Hacking 1990; Porter 1995). Quantitative measures are attractive because numbers combine the properties of order, stability, mobility, combinability and precision (Hansen and Porter 2012; Robson 2012) but the social life that numbers attempt to capture is oftentimes fluid and imprecise. While monitoring systems allow for standardized methods of tracking an intervention which is essential for "scaling-up", it can also have unintended consequences. This paper examines some of those unintended consequences.

We begin by describing the NGO's community-led structural approach to HIV prevention that aimed to create a group of empowered FSWs called "Social Change Agents" (SCAs) and how such an approach guided the development of the community-based monitoring tool for use by SCAs to enhance their participation in program activities. We then present findings that show that despite best intentions and a staff committed to the goals of community empowerment, the quantification processes of monitoring (a) undermined community ownership, (b) discredited existing and locally-informed FSW practices and (c) became the basis to discipline and punish the FSW community. We conclude by considering the lessons that can be drawn from the analysis on the design and implementation of community-based monitoring tools.

\section{THE NGO'S COMMUNITY-LED STRUCTURAL INTERVENTION (CLSI) IN RAJAHMUNDRY:}

2004-2009 
The NGO is one of 130 interventions funded in six high-prevalence states by the Bill \& Melinda Gates Foundation's Avahan India AIDS Initiative. It began operations in Rajahmundry in October 2004. Rajahmundry is a semi-urban town of 400,000 in the largely rural, agriculturally rich East Godavari district in Andhra Pradesh state. East Godavari, of which Rajahmundry is the commercial hub, is among the districts most severely affected by HIV, particularly amongst its FSW population (Rachakulla and et al. 2011). Here and throughout the state, sex work takes different forms, including in brothels, homes, agricultural fields and lodges, on the streets and highways, and in various combinations of these forms (Dandona and et al. 2005).

The NGO used the terminology "Community-Led Structural Intervention" (CLSI) to describe its community-based approach to empower FSWs (Care India 2008). The NGO's intervention combined, from the very start, three elements considered integral to implementing CLSI: control over access to services (through condom distribution and STI treatment); community mobilization (through peer education, community building and formation of sex worker community-based organizations (CBOs)); and creation of an enabling environment by advocating with the police, challenging wrongful police actions, organizing public events to oppose sex worker stigma and media advocacy to encourage positive portrayals of sex work (Biradavolu et al. 2009; Blankenship et al. 2010; Care-Saksham booklet, undated).

The NGO's mandate was to emulate the Sonagachi Project in India that was set up in the early 1990s and is recognized as a successful model for improving condom usage, lowering STIs and HIV, and creating empowered FSWs (Jana et al. 1999; Pardasani 2005; Swendenman et al. 
2009). The NGO, in turn, would serve as a demonstration site from which other implementers in the Avahan program could learn.

The NGO began by identifying 32 FSWs to serve as Social Change Agents (SCAs) and training them to be peer educators and community organizers. The term 'SCA' was a deliberate choice away from the traditional 'peer educators' nomenclature'. Drawing on the participatory education work of Freire (1970), SCAs were conceptualized as 'change agents' who not only educated peers for behavior change but also understood the 'structural determinants of behavior' (Care India 2008, Page 1). Such a conceptualization took into account "socioeconomic contexts, habits, attitudes and emotions....and recognized that powerlessness at the community or group level, and the economic and social conditions inherent to the lack of power, are major risk factors for poor health" (Care India 2008, Page 2). The number of trained SCAs rose to 70 by the end of the first year. Each SCA was responsible for $10 \mathrm{FSWs}$, to cover the approximately $700 \mathrm{FSWs}$ enumerated in the initial round of mapping.

To further empower the FSW community, the NGO's goal was to hand over control of the intervention to a sex worker $\mathrm{CBO}$ they helped initiate, as had been accomplished in Sonagachi through a sex workers' union. For the handover to be a realistic goal, there was a strong recognition among the NGO's senior leadership that the SCAs had to be encouraged, trained and empowered to be at the forefront of all programmatic activities. Therefore, SCAs participated in continuous training workshops on sexual health (to recognize STI symptoms and promote correct condom usage), 'power analysis' (to recognize the importance of power differentials in their home and workplace), interpersonal communication (to convince peers to use condoms and clinical services), advocacy and networking (to effectively communicate with 
powerful groups such as the police, the media, politicians etc.), basic clinical skills (to learn techniques of sterilization of medical instruments, proper disposal of used syringes etc.) and programme management (to gain skills in agenda-setting, running meetings, documenting minutes and creating budgets). The SCAs ran several committees that met on a regular basis to provide input on various programmatic activities, e.g., a health committee on clinical issues and a crisis response committee to tackle violence (Care-Saksham Booklet, undated).

Both field staff and clinic staff worked closely to monitor SCAs' work. Clinic staff, comprising a full-time counselor, an auxiliary nurse midwife (ANM) and a part-time doctor, was responsible for running an STI clinic, stocking and distributing condoms and providing psychological counseling. The field staff was in charge of all non-clinical intervention activities, e.g., overseeing outreach to FSWs peers, running $\mathrm{CBO}$ s, organizing events etc. Both clinic and field staff reported to the NGO's senior staff in the Rajahmundry office, who in turn reported to the NGO's central office in Delhi. Over time some FSW community members were recruited as NGO staff, however, for the time period covered in this paper (2005-2007), there were no staff members who were also FSWs and there was a clear distinction between 'FSW community' and 'NGO staff'." The table below shows the organizational structure.

\section{NGO's Organizational Structure}

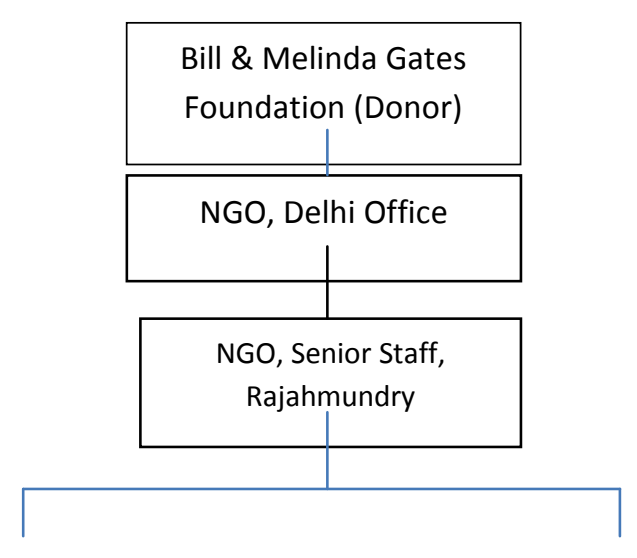




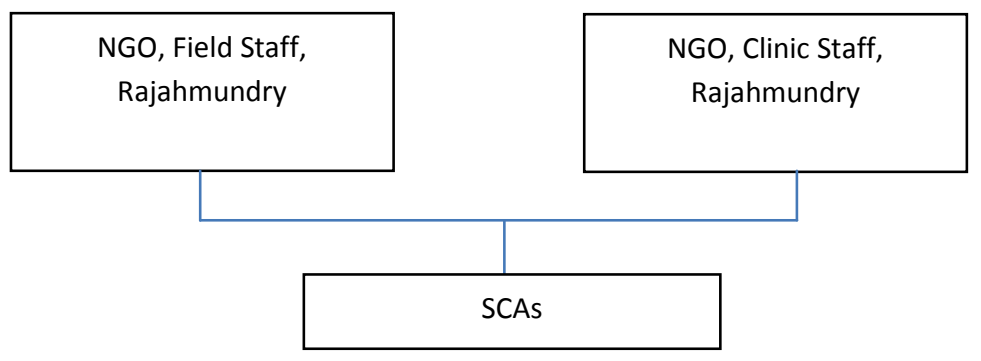

The NGO ran the intervention from 2004-2009. In 2010, the Gates Foundation's Avahan program began phasing out and transferring the administration of interventions to the Government of India (Rao 2010; Sgaeir and et al. 2013). Control over the Rajahmundry intervention has changed hands twice since 2009, but at the time of writing, the handover to the $\mathrm{CBO}$ has not yet occurred.

\section{THE NGO'S COMMUNITY-BASED MONITORING SYSTEM}

Since FSW involvement in all aspects of the intervention was a crucial goal, the NGO created an "SCA Visual Diary" for monitoring purposes that used pictorial representation for ease of use by non-literate FSWs. The Visual Diary was one of a few different monitoring tools developed by the NGO. Clinic staff in the NGO-run STI clinic monitored regular patient checkups using the Clinical Diagnostic Register (CDR) and the Community-based Clinical Register (CBCR). Field staff used the Field Data Entry (FDE) tool to monitor staff activities (Care-Saksham Power Point Presentation 2006). The Visual Diary was the only tool that was implemented by the FSWs themselves and it is the focus of this paper.

The Visual Diary was conceptualized as going hand-in-hand with the overall goals of a community-based intervention. In addition to fulfill the standard monitoring goals of resource tracking, planning and accountability, as stated in an NGO document, the monitoring tool was a mechanism for: (a) ongoing reflection and analysis of experience; (b) collective decision-making 
to improve program performance; (c) capacity building of the skills of the FSW community in program management; and (d) develop a sense of co-ownership of the project (Care-Saksham booklet, undated, Page 18).

The NGO hired a consultancy firm to develop the tool and organized a four-day workshop with SCAs in Rajahmundry in December 2005 to get FSW input on the indicators. The tool was field tested in January 2006 and implementation began soon thereafter.

SCAs were handed the Visual Diary at the start of the month and were expected to turn in the completed diaries at the end of the month to the field staff, who collated the information into a monthly report for the donor. Such tools and data-reporting mechanisms were developed by all NGOs in the Avahan program (Bill \& Melinda Gates Foundation 2008; Bill \& Melinda Gates Foundation 2013).

It is important to note that the Visual Diary's tracking system required the SCAs to count activities in two different ways - individual tracking of peers and case-by-case tracking. The individual tracking of peers was done in the following manner: Each SCA was given stickers of ten different flowers, one each to represent the ten FSWs she was responsible for. The use of flowers allowed non-literate SCAs to use pictorial representations, and for peers to remain anonymous in the tracking systems.

There were three activities an SCA tracked on an individual peer basis: condom distribution, discussions on HIV-related matters and referring/accompanying peers to the NGOrun STI clinic. When the SCA conducted any one of these activities, she was expected to place a check mark against the flower symbol that represented that particular peer. The Visual Diary also collected data on the number of daily sexual encounters per peer and whether a condom 
was used for the sex act. This information was considered vital to understand how many condoms the NGO must make available to each SCA for distribution as well as provide numbers on frequency of condom usage.

The second type of counting was conducted on a case-by-case basis for the following activities: tracking violence, provision of services (other than condom provision and STI services) and organizing meetings. To track violence and harassment, the SCA tracked every case that came to her attention (without attributing the case to any individual sex worker), and action taken (or not), in instances of violence or harassment by police, hooligan, partner and client. The SCA also counted trafficking cases that came to her attention. To track provision of services, the SCAs counted the number of visits she made to peers in the hospital or jail, and the number of times a peer was helped in a bank, post office transaction and to obtain an identification document such as a ration card. The check mark was for a visit made, without indicating which sex worker peer was visited or helped. The SCA also tracked any meeting she organized or facilitated with police, government officials, health care providers and other higher officials.

Three aspects of the tool are worth highlighting. First, the activities included in the monitoring tool highlight how the SCA's scope of activities went beyond traditional peer education. She was expected to confront issues of violence and harassment, both domestic and work-related, including intolerance for trafficking of women; she was trained to advocate with powerful state actors; and she was a frontline support for peers to demand various rights. Thus, as her title suggests, the SCA was an agent for social, political and economic change. 
Second, as described above, certain activities were tracked for each of the ten FSW peers an SCA worked with, whereas other activities were delinked from individual tracking and were reported on a case-by-case basis. Our data show that SCAs repeatedly raised concerns on the challenges they faced in the individual tracking system.

Third, the Visual Diary was developed and implemented a little more than a year after the NGO began its work. Before the Visual Diary, NGO staff monitored SCA activities using a format that did not track every peer an SCA was responsible for. For example, an SCA's monthly condom distribution figures was monitored by simply tracking how many condoms an SCA obtained from the NGO every month rather than calculating how many condoms an SCA distributed to each of her individual peers. Similarly, to determine how many condoms the clinic needed to stock, the NGO used estimates of potential number of sex acts rather than enter precise numbers of sexual encounters into a monitoring tool. We shall return to these examples that point to evolving indicators and tools, and the unintended impact on the need for increased quantification, in the findings presented in Section 5a.

Therefore, the paper focuses on two activities that required individual counts - condom distribution and condom needs assessment. Our analyses show how the radical potential of a tool meant to enhance community ownership was undermined in the pressure to fit flexible sex work practices within the fixed tracking systems instituted by the monitoring tool.

\section{DATA AND METHODS}

Data are drawn from Project Parivartan, a multi-methods study, supported by the Bill \& Melinda Gates Foundation, to analyze the process and impact of community mobilization interventions that aim to reduce HIV risk and vulnerabilities among FSWs in Andhra Pradesh, 
India. Project Parivartan's research began around the same time that the NGO started operations, but Parivartan's team worked independently of the NGO - it had no implementation responsibilities. Parivartan's staff consisted of a team of experienced researchers and there was no overlap in the staff of Parivartan and the NGO. The research staff in Rajahmundry comprised five ethnographers, including two authors of this paper who supervised all field activities. The five-person team gathered all the qualitative data.

The ethnographic dataset that this paper relies on comprises longitudinal data collected continuously for over 2 years from 2005-2007. We conducted observations on a near-daily basis on a broad range of $\mathrm{NGO}$ and $\mathrm{CBO}$ activities related to community mobilization. The data also include key informant interviews with NGO staff, sex workers, their intimate partners, lawyers, police, madams, other brokers and clients. Efforts were made to get a representative sample of sex workers by approaching women at their work sites and not limiting study participants to only those who frequented the NGO office. Finally, we also conducted longitudinal interviews with sex workers with varying degrees of involvement with the intervention. The specific data used for this paper is explained below in greater detail.

Ethical approval was obtained at the Institutional Review Boards of Yale University, Duke University, American University and through YRG Care, a research institution in India.

\section{(a) Observations of NGO and CBO meetings}

When the study began, every attempt was made to observe as many of the NGO and CBO activities as possible. Over time, as the NGO's and CBO's work became more systematic, we selectively observed key meetings. These included weekly NGO staff meetings (which became monthly meetings over time), weekly meetings of the executive body of the CBO, once- 
a-month meetings of all SCAs and any trainings, workshops and public events. These meetings typically lasted from between half-a-day to a full working day, covering a range of issues.

For this paper, we began by including notes on the full set of monthly NGO staff meetings from 2005 to 2007 ( $n=27)$, monthly meetings of SCAs over the same 2 year period $(n=22)$, and meetings of the FSW CBO's executive body from 2005-2007 ( $n=40)$. Not all these meetings included discussions on the Visual Diary. Therefore, the total of 89 observations were searched using keywords related to monitoring, including some that are specific to the local context (Visual Diary, CBMS, Monitor, Evaluate, Documentation, Register, Check, Record, Review, Data, Performance, Format, System, MIS, Database, Flower). The word search whittled down the total number of files to 37 (7 NGO staff meetings, 10 SCA monthly meetings and 20 meetings of Nari-Saksham's executive body). In addition, three meetings to develop the tool in December 2005 and three to field test the tool in January 2006 were observed and recorded by Parivartan ethnographers. In sum, 43 observational notes are included in the final analysis.

\section{(b) Semi-structured interviews}

The data also comprises the second of three rounds of longitudinal semi-structured interviews conducted between October 2005 and March 2007, with FSWs with varying degrees of involvement with the NGO. With the help of NGO staff, we determined there were four possible levels of involvement: SCAs in leadership positions, SCAs without any leadership position, FSWs who were not SCAs but had CBO affiliation and finally, those who had no affiliation with either the NGO or any $\mathrm{CBO}$. Only the second of three rounds of interviews was analyzed because of the inclusion of questions related to the Visual Diary. The guides for this research component were directly informed by observational data. Since concerns about the 
Visual Diary were being discussed in the staff, SCA and CBO meetings around the time of the second round of this research component, we queried respondents about their experiences.

There were 17 interviews in total, by which time the SCAs had been using the Visual Diary from between 4-6 months. Interviews lasted up to 2 hours, were conducted in the Parivartan office after taking informed consent, audio-recorded and transcribed from Telugu to English. The interview dataset also include three interviews with NGO staff where monitoring issues are specifically discussed.

\section{(c) NGO Documents}

We also analyzed six NGO-produced documents related to the Visual Diary, including Power Point slides to show visitors, NGO plan of action and monthly reports generated by staff to send to the donor.

\section{(d) Data Analysis}

For the analysis, the compiled observational data were read and re-read to find emerging themes, relationships and patterns. The observational notes were also read sequentially in time because issues raised in one type of meeting would recur in another, e.g., concerns raised by SCAs in their monthly meeting would be discussed amongst staff at the staff meeting. Or, a problem that arose at one point could be followed to see if it was resolved at some future point in time. The interview transcripts were read for relevant discussions on monitoring.

The ethnographic data generated was vast. To keep track, analyses occurred at different stages throughout the research process. The research staff in India conducted weekly meetings to discuss and share findings with the U.S.-based research team. These meetings were a forum 
for ethnographers to report, reflect on, and discuss NGO and CBO activities. Minutes of these meetings were compiled into monthly reports that summarized observational data over time. The Parivartan team also maintained active engagement with the NGO and CBO. For example, interview guides were shared with NGO staff and their input sought. At monthly NGO meetings, Parivartan staff provided feedback on data collection activities with implications for the intervention and periodically, they gave presentations on major findings to both the NGO and $\mathrm{CBO}$.

\section{FINDINGS}

\section{(a) Monitoring condom distribution, Undermining community ownership}

Condom use is considered a "critical element in a comprehensive, effective and sustainable approach to HIV prevention and treatment" (UNAIDS 2009). Accordingly, condom distribution to FSW peers was a key responsibility of SCAs and monitoring condom distribution was included as an activity for SCAs to track in the community-based monitoring tool. SCAs did so by filling out their Visual Diaries on a daily basis, and placed a check mark against each of her ten peers who received condoms from her. However, SCAs reported problems in completing this task, arguing that because sex workers were mobile and frequently worked in more than one area, it was difficult to provide condoms to FSWs as they moved across sex work sitesii. As a result, the SCA did not always know where to find all her peers or how to enter the correct information in her diary, as evidenced in the quote below.

SCA: Some sex workers are not coming to Isukaveedi but operating from Tummalova or Devichowk. They are taking condoms from me as well as from another SCA who works in Tummalova. What should I do? When sex workers practice in more than one place, they take condoms from more than one SCA. When they return to Isukaveedi, they take condoms from me. What shall I write about them? 
Isukaveedi, a well-known brothel site in Rajahmundry, is in a prime real estate location and the brothel owners face near-daily pressure from police and local politicians to stop sex work. In the quote above, the SCA highlights that policing practices were forcing FSWs to switch between three different sex work sites in Rajahmundry - Isukaveedi, Tummalova and Devichowk - and, as sex workers moved, they found SCAs in each of those locations to obtain condoms from. However, the movement constrained SCAs' ability to track the women. The SCA could not mark that she had provided condoms to her peer who had moved to another site because that would be an inaccuracy. However, leaving a blank for that peer was also inaccurate because that data would suggest that the FSW had not received condoms at all whereas she may have obtained condoms from another SCA.

Similarly, another SCA explained her predicament of providing condoms to women who avoided police problems by opting for contract work, referring to the practice of short visits for a fixed number of days in return for a fixed income:

SCA: Many sex workers are not staying at their place in Tummalova. They are going to Kovvuru and coming back after 15 days. They are doing so because of police problems. What should we do? I do not know whether they are getting condoms from somewhere or if some other SCA there is providing her condoms.

The NGO staff provided a solution to SCAs: provide condoms ahead of time to those women who informed their SCAs about their trips. However, staff also instructed:

There should be no overlap of sex workers between SCAs. In the first interaction, ask the sex worker whether she is associated with any SCA. If she does not associate with any $S C A$, then provide her with condoms. 
By telling the SCA that she should not provide condoms to a peer who may be preassigned to another SCA, the staff member ensures that there is no double counting and that all SCAs can neatly fill out their diaries according to the fixed and orderly parameters of only tracking their ten assigned sex workers every month. Yet, the advice violates core intervention goals. To achieve easy availability and accessibility of condoms that the intervention desired, it should not matter from where (or which SCA) the sex worker obtained her condoms. Insisting on only providing condoms to pre-assigned peers was adding, not dismantling, barriers to condom availability. Rather than devise solutions that fit the local reality of sex workers' mobility, the staff's approach was to prioritize the fixed tracking system of the Visual Diary.

It is instructive to consider how condom distribution was monitored prior to instituting the Visual Diary. Every month, the NGO staff in Rajahmundry filled out a Monthly Report to send to their office in Delhi in which they reported "number of condoms distributed". Staff maintained figures on condom stock and derived the total number of condoms distributed by subtracting the total stock at the end of the month from the stock at the start of the month. Staff also tracked how many condoms they gave to each SCA every month but there was no tracking of who the SCAs gave condoms to. It was understood that the SCA would give condoms liberally - that is, to all of her assigned peers as well as to whichever other sex worker asked her for it.

The advantage of such a system was that the SCAs gave condoms to whomever they encountered without worrying about whether the woman was one of her assigned ten, thereby jointly sharing the responsibility of condom provision for peers, a system that aligned more closely with the principles of community mobilization and community ownership. When sex 
workers' condom needs were covered by a group and not just a single SCA, sex worker mobility did not matter. What mattered was whether sex workers would be able to find SCAs to obtain condoms from no matter where they conducted their business. As long as all SCAs jointly took responsibility of possible sex work locations, at least in theory, the intervention's goals of condom distribution would be met.

The Visual Diary's individual (as opposed to community) tracking for condom distribution also served its own purposes: first, each SCA's work could be tracked to improve individual accountability; second, each FSW peer was tracked individually in order to assess who was being reached on a regular basis, and if the data showed systematic gaps in delivery, to understand reasons and take corrective action; and third, from a program management perspective, it is simpler to track individuals. Yet, ironically, the individual tracking in the Visual Diary in fact dismantled the NGO's pre-existing community-based system of condom distribution. Rather than account for a key feature of sex workers' lives -mobility across sex work locations - and have this be reflected in the monitoring tools, the SCAs were instead instructed by staff to comply with a rigid system of condom distribution that only allowed them to give condoms to their assigned peers.

Another section in the Visual Diary that SCAs reported as challenging was designed for the dual purpose of assessing condom needs and to track whether there was an increase in condom usage. Similar to the monitoring of condom distribution, the data had to be collected at the level of each individual by tracking every sex act and marking whether a condom had been used during the encounter. In the following section, we consider how the requirement to gather such data ultimately undermined SCAs' understanding of the local context of sex work, 
questioned the SCA's ability to assess her own community's needs and set up the SCAs to undertake a near-impossible task.

\section{(b) Condoms are not commodities: Challenges of doing "condom needs assessment"}

Prior to instituting the Visual Diary, condom needs assessment (the number of condoms the intervention had to make available to SCAs to ensure condom availability for all FSWs) was assessed based on an understanding of individual SCAs' context of sex work. Clinic staff, responsible for stocking, tracking and distributing condoms to SCAs explained the system in the following manner:

Condoms are obtained from the government health facility and stocked in the clinic. On the day of the SCA Monthly Meeting, I hand over condoms to each SCA for the whole month. During the month if they fall short, they come back to take more. The number is not fixed for all the SCAs. Secret ${ }^{i i i}$ sex workers who work in houses have limited clients and use fewer condoms whereas highway sex workers use more condoms. Highway SCAs take 500 condoms and that may not be enough for the whole month whereas SCAs who work for secret sex workers take 150 per month.

The clinic staff's system of condom distribution to SCAs rested on an estimation of client volume at different sex work sites. There was an understanding that if an SCA needed more during the course of the month than the staff had estimated, the SCA could always return to the clinic and ask for more. Staff used a simple reporting format: subtracting the total stock at the end of the month from the total at the start of the month.

Increasingly, however, the NGO felt pressured by a data-driven donor to replace the existing system of approximating condom needs with a system based on better data-tracking 
mechanisms on condom requirement. From the donor's perspective, one year into the Avahan program, the data from all funded NGOs across the six states showed two positive metrics one, an increase in numbers of total sex workers contacted, and an increase in numbers of condoms distributed. However, a review of the data also showed two trends that needed course correction: first, that condom distribution was still being done by NGO staff, not sex worker peers. Secondly, even though the numbers of condoms distributed was increasing, the numbers were still vastly inadequate to cover all the commercial sex acts that were estimated based on profiling information gathered at the start of the unfolding of the Avahan program. The donor determined that the NGOs were grossly underestimating condom needs. The donor asked the NGOs to estimate correctly the gap in condom need and condom distribution and to fill the gap to ensure full coverage. ${ }^{\text {iv }}$ What we present in this section is how the NGO in this case study translated this donor requirement on the ground.

The excerpt below from a staff meeting highlights that the NGO understood the importance of data collection for HIV prevention, including assessing condom requirement and usage:

NGO Senior staff: We can have narratives about CBO meetings, rallies etc. But for the prevention of HIV/STDs, we need specific concrete data. In the meetings with SCAs, staff should focus on data on STIs (sexually transmitted infections) and condom usage. The first thing is an assessment of condom needs. Ask them the number of clients and the number of encounters per week.

It is clear from the excerpt above that for some intervention activities, including condom needs and usage, the NGO understood that it was necessary to produce numeric data 
in contrast with initiatives such as "CBO meetings" and "rallies" where "narrative" data would suffice. The senior staff further explained that numbers were necessary to demonstrate the intervention's success to donors:

We get a firing from the donors that condom usage has not increased, but it is not actually true... we have not been able to document it properly.

Thus, a section in the Visual Diary was developed to gather data with the purpose of estimating condom requirements and to do this, SCAs were required to track the daily number of sex acts by FSWs and mark with a check when a condom was used and a cross when it was an unprotected sex act.

However, explaining the need for such data to SCAs, as well as collecting it, was far from smooth. Consider the following excerpt, which is an exchange between the staff and an SCA at a meeting held to understand how SCAs were using the Visual Diary:

Staff: How many condoms do you have in your house?

SCA: $A$ hundred

Staff: Did you take any condoms this month?

SCA: This month I have not taken since I already have a hundred at home.

Staff: How do you calculate the need for condoms?

SCA: Whenever a sex worker asks me for condoms, I give it to them.

Staff: If you do not know how many condoms sex workers use, then how do you calculate? Do you maintain an account in the Visual Diary of how many condoms are needed for sex workers in one month?

SCA: Some months sex workers need 20, and some months more than 20. 
Staff: But what is the system?

SCA: I rent rooms for sex workers to conduct their business. So the system is that the sex worker comes for condoms before the encounter. Some sex workers also bring condoms with them, so I don't need to give them any. Some other sex workers who do not come to my house for sex work, I also give them condoms.

Staff: What I am observing is that there is no planning and no system for condom distribution and assessment. With your income, you do some calculation on how much you spend. Whether literate or illiterate, every human being has the capacity to count. SCAs should use the Visual Diary to calculate. You should have some knowledge of how many condoms on average are needed for each sex worker.

The staff erroneously assumes that there is no system by which the SCA assesses condom requirement and that the SCA does not know how to count. In fact, the SCA's 'system' is to calculate based on her knowledge that the business is fluid, where the number of clients is not fixed and the situation of condom provision is variable. Therefore, the SCA 'counts' and arrives at estimates, not precise numbers. With a hundred condoms at home, the SCA has a sufficient number for one month and does not feel the need to fill out the Visual Diary to arrive at this conclusion. However, without the numbers entered into the Visual Diary, staff dismisses the SCA's method of assessing condom requirement and is unconvinced that the estimates of the SCA are valid.

Another staff person, listening to the exchange, attempts to simplify matters for the SCA by providing an analogy: 
Staff to SCA: When you buy grocery items, you make some calculation and figure out that specific kilograms of rice are required and have a sense of when that rice will get over.

SCA: It is not the same as buying grocery items for the home. Business and daily needs are very different. Rice is needed every day since we eat food every day and we cannot survive without it. But in the case of business, and also of using condoms, it is not fixed since one day we will have good business if customers come and some days we do not have any business. Rice and business are not equal.

Staff: You should have a rough idea. And this is not your first day of working as SCAs. You have been working as SCAs for the past 1 or 2 years. It is high time that you used the Visual Diary and learnt to do some calculation regarding condom distribution.

In the exchange above, the staff person equates counting kilograms of rice with counting condoms for client encounters, and regards the two commodities as commensurate, i.e., their values can be compared using a common metric that make comparisons easier (Espeland and Stevens 1998). However, the SCA rejects the comparison by stating that "rice and business are not equal", arguing that the need for rice is fixed and predictable as survival without it is impossible, but the need for condoms is variable as business is unpredictable.

By insisting that the SCA use the Visual Diary, and reprimanding the SCA for not doing so, the staff prioritizes data generated by the monitoring tool. Discrediting the SCA's counts, which are based on the SCA's intimate knowledge of the sex business at her site and among her peers, runs counter to the intervention's principle of the SCA being the rightful intermediary between the intervention and the FSW community. Instead of taking the SCA's local knowledge 
into account and devising a system that relied on existing ways of assessing condom needs and usage among the FSW community, the NGO imposed a system of data generation that was resisted by SCAs.

Unsurprisingly, the actual task of filling out the Visual Diary on condom usage was challenging for the SCAs, as was revealed in an interview:

Does anyone tell such details? If a girl has sex 10 times, does she tell the number correctly? She will say once. If a sex worker has good business, then she is afraid that others, out of jealousy, might cast an evil eye on her business so she does not reveal the actual number of clients she gets. They say, "Who are you to ask me? Just give your condoms and go."

Sex worker peers resisted SCAs' questions on condom usage as it revealed business details that they were unwilling to share. When the interviewer asked the SCA how, given the situation described above, she enters numbers in the Visual Diary, she said:

The staff said if they say once, write two times but don't ask and trouble them.

In the end, even with the use of the Visual Diary, SCAs continued to estimate condom requirement among her peers. At the field level, the NGO staff understood the near impossible task of measuring condom usage with finitude. Therefore, the staff's solution was to instruct the SCA to continue what she was doing before. Nothing changed in how condoms were counted, but two things changed: one, an important process of involving the SCAs in project implementation was lost and second, the SCA was forced to falsify information she entered into the Visual Diary. By delegitimizing the SCAs' system of estimating condom needs, the NGO violated its own goals of instituting a participatory and "community-based" monitoring system. 
The next section highlights how discrediting SCAs' claims impacted FSW views on the purpose of the Visual Diary. The NGO staff too did not have uniform opinions.

\section{(c) Monitoring to discipline and judge}

For the NGO's senior staff, the Visual Diary was part of the package of activities to implement a community-led structural intervention that would enhance participation and improve SCAs' program management skills:

Senior staff: The community should do monitoring activities, not the staff. We want to implement a community-led programme, not a staff-led programme. The data gathering is FSW' responsibility so that after the NGO leaves, they would be able to run the project. The whole intention is not to do monitoring but to give proper direction to the program... The Visual Diary is not meant for the SCAs to fill out mechanically.

The senior staff believed that the field staff had not communicated the purpose of the Visual Diary to the SCAs, while acknowledging that the field staff too lacked sufficient training from their superiors and were burdened with many other activities. The NGO's senior staff repeated to the field staff that the Visual Diary was "not for checking SCAs' work". This only served to confuse field staff, who considered the Visual Diary to be a tool to monitor SCAs and discipline those who, in their view, were shirking work. The Visual Diary's connection with community mobilization was unclear.

At a staff meeting, a field staff asked the senior staff whether further training of SCAs on the goals of the Visual Diary should be undertaken at the expense of organizing CBO activities. The senior staff had a hard time clarifying that community-based monitoring was not separate 
from, but inextricably linked with, community mobilization and CBO activities. Here is an example of how field staff communicated monitoring data to SCAs:

In the clinic database there are 157 brothel sex workers, 104 street sex workers, 343 home sex workers and 116 highway sex workers and all total there are 720 sex workers. But the SCAs' Visual Diaries add up to a total of 900 sex workers. So there is a discrepancy of 180 sex workers who are "ghost" or "missing" sex workers.

Since quantitative measures are a key mechanism for simplifying, classifying, comparing and evaluating, which are at the heart of disciplinary power (Espeland and Vannebo 2008), field staff used data collected through the clinic database against the data in the Visual Diary to question, judge and control SCAs. The following exchange is also indicative of the way SCAs were judged on their performance:

Field staff: Every month, the performance of the SCAs is recorded in the clinic. It is found that SCAs are not doing quality work. So there will be new systems in place. There will be a grading system - I, II and III grades. SCA from Thadithota brought only 3 sex workers to the clinic.

SCA from Thadithota: I brought five people because two days back, I brought two. I reported it in my Visual Diary. My supervisor [NGO field staff] knows about it.

Clinic staff: You may be reporting it to your supervisor and it might be in the Visual Diary but the patients you brought are from out of your coverage area. Clinic data shows that she is not your usual sex worker. From your coverage area you brought only three. We have a separate system for everything. After you fill up the Visual Diary, the Field staff verifies it against the clinic record. 
The field staff used the data in the Visual Diary to invalidate SCAs' accounts of the work they did, separating SCAs into those who met predetermined targets and were "doing quality work" from those viewed as derelict in their responsibilities. The SCAs too were divided in their views on the Visual Diary. Some were pleased with the tool's ability to discipline SCAs. The following is an excerpt from an observational note of the sex worker CBO's executive body meeting:

The members noted that some SCAs work harder than others but all get the same pay.

They decided that SCA salaries should not be linked with the reports of field staff. Instead, the salaries should be given based on the Visual Diary filled out by SCAs.

In interviews, SCAs were asked why they were entering data into the Visual Diary. Women spoke in terms of accountability and legitimacy, as expressed below:

The diary is proof that we have done the work. Neither the NGO nor the government will know I am working if I just say it with words.

However, none expressed ownership of the data or articulated how the data collection helped increase sex worker involvement in the intervention or helped in future planning. When asked what was done with the visual diaries after the SCAs had filled them out, the following series of responses by different SCAs show the divergence between the rationale for setting up a community-based monitoring system as a tool to help "reflect, learn and refine program strategies" (Care-Saksham Booklet, undated), and the reality on the ground:

Whoever does not fill them up, will be removed from the SCA post. It is useful for the NGO, not us.

We don't know what they do with it afterwards. It goes to the higher-ups. 
Someone must have made it compulsory so they are asking us to do it in this method.

It has no connection with the life of sex workers. For us SCAs also it is not very useful.

Of what use is this for the sex workers we are working with?" I asked them [the NGO].

They said it goes to Delhi after they check it.

The sharp divergence on the purpose of the Visual Diary among staff and SCAs grants both researchers and practitioners an opportunity to consider the lessons that can be learned from the NGO's experience in implementing a community-based monitoring system.

\section{DISCUSSION \& CONCLUSION}

By highlighting the challenges faced in the implementation of the Visual Diary, it is not our intention to question the NGO's overall goal to implement a community-led structural intervention and devise a monitoring system that embodied this objective, or suggest that the NGO or CBO did not conduct a range of other activities that did, in fact, empower FSWs. Rather, the paper demonstrates the unintended consequences of one aspect of the NGO's activities, i.e., the quantification imperative of monitoring systems. In the tension between the need to gather data using quantitative measures that were simple and easy to produce and the complex reality of local, fluid sex work practices, the key actors lost sight of the original objectives of community ownership and participation.

The perils of quantifying complex social interactions and the challenges of implementing monitoring tools are systemic issues that are not just faced by a single NGO. It is important to point out that even though the paper uses data on one NGO, this case study should be the basis to understand the larger problem at hand. By granting researchers full access to their activities, the NGO showed openness and a spirit of learning. There is very little evidence from other 
NGOs' experience of using similar community-based monitoring tools because there is very little process data that is being gathered on their implementation activities. Therefore, the paper highlights the pressing need to include process data using qualitative methods to understand implementation challenges, in addition to understanding impact of interventions. And, rather than turn the evidence and narrative into one NGO's shortcomings, it is instead critical to consider some of the broader lessons that can be drawn on how community-based monitoring systems can best live up to their potential.

First, the paper does not argue against the use of quantitative measures for monitoring; indeed such measures are important to assess health impacts (Glassman et al. 2013), to track the flow of resources and for "micro-planning" (Avahan 2013). However, indicators must be meaningful and locally relevant. The lesson that can be drawn from this experience is that while numbers are efficient and transparent, the act of counting is never simple or neutral. FSW input was sought during the development and testing of the Visual Diary on certain issues, e.g., whether the pictorial indicators were easy to comprehend by a non-literate population or whether the frequency of measurement of indicators was adequate. Yet, the community was not asked a more fundamental question: whether it was even possible or sensible to measure and quantify certain social interactions.

Second, while the NGO put time and effort in developing the tool, and even had forums where SCAs could raise concerns freely, there was no feedback loop that allowed concerns to effect a change in strategy. The Visual Diary had the potential to be used for "evidence-based learning "or "learning from failure" that development programs and scholars recommend (Claeson and Alexander 2008; Mansuri and Rao 2012; Millennium Challenge Corporation 2012). 
However, without constant attention, feedback mechanisms, and importantly, buy-in from all links in the donor chain (Jacobs 2010), the Visual Diary came to be viewed by the SCAs as an imposition that served the interests of outsiders, but not the community members themselves.

Third, the NGO resisted the SCAs' challenge to their authority because it too faced pressures to demonstrate with "concrete data" an increase in condom distribution. The NGO felt that the way to demonstrate success was by producing numbers. When SCAs resisted the quantification process, the NGO questioned the SCAs' logic instead of re-examining the indicators in the tool. To truly engage in "learning from failure", there needs to be a shift in approach where interventions are encouraged to be able to report on challenges, both to allow change in course and also so that others may learn from their experience.

Finally, large-scale donor programs typically involve several layers of implementing partners. Achieving a balance between scaling-up and tracking individual interventions on the ground is a huge challenge; yet, the very real possibility of losing nuance as instructions are translated on the ground should be anticipated, acknowledged and built into intervention programs. The field staff that had the most direct contact with the SCAs did not have clarity on how monitoring systems link with community organizing. As a result, the NGO staff used the tool as a disciplinary instrument and SCAs did not view the monitoring activities as connected with the development of their $\mathrm{CBO}$ or empowering them to participate in the intervention.

It is not enough to introduce community-based monitoring tools to enhance community involvement in development programs. This paper highlights that the Visual Diary ultimately fell short of its ideals because of the challenges in implementing the tool and lack of attention to the context of sex workers lives. The full potential of such tools can only be realized through 
careful consideration of indicators selected by the community, understanding the unintended consequences of the quantification process, training all key actors in the underlying principles of such tools and the creation of feedback loops that allow community voices to effect midcourses corrections in program design.

\section{REFERENCES}

Appadurai, A. (1993). Numbers in the colonial imagination. In C. A. Breckenridge \& P. Van der Veer (Eds.), Orientalism and the postcolonial predicament: Perspectives on South Asia. Philadelphia: University of Pennsylvania Press.

Afridi, F. (2008). Can community monitoring improve the accountability of public officials? Economic and Political Weekly, 43, 35-40.

Bill \& Melinda Gates Foundation (2008). Use it or lose it: How Avahan used data to shape its HIV prevention efforts. New Delhi: Bill \& Melinda Gates Foundation. Available from https://docs.gatesfoundation.org/Documents/avahan useitorlooseit.pdf

Bill \& Melinda Gates Foundation (2013). Micro-Planning in peer led outreach programs - A handbook. New Delhi: Bill \& Melinda Gates Foundation. Available from http://futuresgroup.com/files/publications/Microplanning Handbook (Web).pdf

Biradavolu, M.R., Burris, S., George, A., Jena, A., \& Blankenship, K.M. (2009). Can sex workers regulate police? Learning from HIV prevention project for sex workers in southern India. Social Science and Medicine, 68(8), 1541-1547.

Björkman, M., \& Svensson, J. (2009). Power to the people: Evidence from a randomized field experiment on community-based monitoring in Uganda. The Quarterly Journal of Economics, May, 735-769. 
Blankenship, K. M., Biradavolu, M.R., Jena, A., \& George, A. (2010). Challenging the stigmatization of female sex workers through a community-led structural intervention: learning from the case study of a female sex worker intervention in Andhra Pradesh, India. AIDS Care, 22 (1), 1629-1636.

Blankenship, K.M., Bray, S.J., \& Merson, M.M. (2000). Structural interventions in public health." AIDS, 14 (Suppl 1), 11-21.

Buzdugan, R., Copas, A., Moses, S., Blanchard, J., Isac, S., Ramesh, B.M., Washington, R., Halli, S.S., Cowan, F. (2010). Devising a female sex work typology using data from Karnataka, India. International Journal of Epidemiology, 39(2), 439-448.

Care India. (2008). Development and management of Social Change Agents. New Delhi: CARE India. Available from

http://www.careindia.org/sites/default/files/pdf file/6\%20Development\%20and\%20Managem ent\%20of\%20Social\%20Change\%20Agents.pdf

Care-Saksham Booklet (undated). Where dreams unfurl: The SAKSHAM initiative in East Godavari. A booklet produced by Care-Saksham. Available from http://www.indiahiv.org/Documents/Revised\%20Booklet SAKSHAM.pdf

Claeson, M. \& Alexander, A. (2008). Tackling HIV in India: Evidence-based priority setting and programming. Health Affairs, 27(4), 1091-1102.

Cohn, B. (1984). The census, social structure and objectification in South India in culture and history of India. Folk, 26, 25-49. 
Dandona R., Dandona, L., Gutierrez, J.P., Kumar, G.A., McPherson, S., Samuels, F., Bertozzi, S. and the ASCI FPP Study Team. (2005). High risk of HIV in non-brothel based female sex workers in India. BMC Public Health, 5:87, 1-10.

Espeland, W.N. \& Stevens, M.L. (1998). Commensuration as a social process. Annual Review of Sociology, 24, 313-343.

Espeland, W.N. \& Stevens, M.L. (2008). A sociology of quantification. European Journal of Sociology, 49 (3), 401-436.

Espeland, W.N. \& Vannebo, B.I. (2008). Accountability, quantification and law. Annual Review of Law and Social Science, 3, 21-43.

Estrella, M., \& Gaventa, J. (1998). Who counts reality? Participatory monitoring and evaluation: a literature review. Vol 70. Brighton: Institute of Development Studies.

Freire, P. (1970). Pedagogy of the oppressed. New York: Continuum.

Glassman, A., Fan, V. \& Over, M. (2013). More health for the money: Putting incentives to work for the Global Fund and its partners. Washington, DC: Center for Global Development [WWW page] http://www.cgdev.org/sites/default/files/More-Health-for-the-Money.pdf Hacking, lan. (1990). The Taming of Chance. Cambridge: University of Cambridge Press.

Hansen, H.K. \& Porter, T. (2012). What do numbers do in transnational governance? International Political Sociology, 6(4), 409-426.

Jacobs, A. (2010). Creating the missing feedback loop. IDS Bulletin, 41(6), 56-64.

Jain, A. \& Saggurti, N. (2012). The extent and nature of fluidity in typologies of female sex work in southern India: Implications for HIV prevention programs. Journal of HIV/AIDS \& Social Services, 11(2), 169-191. 
Jana, S., Bandyopadhyay, N., Saha, A., \& Dutta, M.K. (1999). Creating an enabling environment: Lessons learnt from the Sonagachi Project, India. Research for Sex Work, 2, 22-24.

Mansuri, G. \& Rao, V. (2012). Localizing development: Does participation work? [WWW page] Available from http://econ.worldbank.org/localizingdevelopment

Millennium Challenge Corporation (2012). MCC's first impact evaluations: Farmer training activities in five countries. [WWW page] Available from http://www.mcc.gov/documents/reports/issuebrief-2012002119501-ag-impact-evals.pdf Pardasani, M.P. (2005). HIV prevention and sex workers: An international lesson in empowerment. International Journal of Social Welfare, 14 (2), 116-126.

Porter, T. M. (1995). Trust in Numbers: The Pursuit of Objectivity in Science and Public Life. Princeton: Princeton University Press.

Rachakulla, H.K., Kodavalla, V., Rajkumar, H., Prasad, S.P., Kallam, S., Goswami, P., Dale, J., Adhikary, R., Paranjape, R., \& Brahmam, G.N. (2011). Condom use and prevalence of syphilis and HIV among female sex workers in Andhra Pradesh, India - following a largescale HIV prevention intervention, BMC Public Health, 11 (Suppl 6), S1.

Rao, P.J.V.R. (2010). Avahan: The transition to a publicly funded programme as a next stage. Sexually Transmitted Infections, 86 (1): i7-i8.

Sgaeir, S.K., Ramakrishnan, A., Dhingra, N., Wadhwani, A., Alexander, A., Bennett, S., Bhalla, A., Kumta, S., Jayaram, M., Gupta, P., Piot, P.K., Bertozzi, S.M., \& Anthony, J. (2013). How the Avahan HIV program transitioned from the Gates Foundation to the Government of India. Health Affairs, 32(7): 1265-1273. 
Swendenman, D., Basu, I., Das, S., Jana, S., \& Rotheram-Borus, M.J. (2009). Empowering sex

workers in India to reduce vulnerability to HIV and sexually transmitted diseases. Social

Science and Medicine, 69 (8), 1157-66.

UNAIDS. Condoms and HIV prevention. (2009). [WWW page] Available from

http://data.unaids.org/pub/BaseDocument/2009/20090318 position paper condoms en.pdf

Van Risjoort, J., \& Jinfeng, Z. (2005). Participatory resource monitoring as a means for

promoting social change in Yunnan, China. Biodiversity and Conservation, 14, 2543-

2573.

\footnotetext{
"While the NGO made some effort to use terms in the local language, in this particular case, the term "SCA" was not translated. The FSW community used the English term "SCA". From time-to-time the NGO staff explained the meaning and relevance of the English term "Social Change Agent" and made efforts to tell the FSW community how an "SCA" was different from a "Peer Educator".

ii Research on sex work in India has documented how FSWs move between venues to practice their trade and oftentimes, solicit in one type of sex work setting while entertaining in another (Buzdugan 2010; Jain and Saggurti 2012)

iii The English term 'secret sex worker' is used by NGO staff and increasingly by FSWs themselves. It typically refers to women who make an effort to hide their sex work identity by working in non-descript homes that do not appear to be locations where sex work is conducted, avoiding the more 'public' sex work venues such as the streets, highways or brothels or by working in areas that are at a distance from where they reside.

iv Based on personal communication on January 20, 2012, with G.Dallabetta, Senior Program Officer, The Bill \& Melinda Gates Foundation
} 


\begin{abstract}
Studies have examined whether community-based monitoring systems impact desired program outcomes, but few provide field-based evidence on the implementation process itself. This paper fills the gap using ethnographic data on the community-based monitoring tools developed by an HIV prevention NGO for sex workers in south India. The tool was well conceptualized, with potential to enhance community participation in program design. Yet, despite best intentions, our findings show that the quantification process undermined community ownership, discredited existing and locally-informed sex work practices and, rather than empowering, monitoring became a means to discipline and judge sex worker peer educators.
\end{abstract}




\section{Acknowledgments}

The authors thank Asima Jena, PJ Manohar and Prem Garudadri for their able assistance in field work and Biju Rao for comments on draft versions of the paper. Support for this research was provided by the Bill \& Melinda Gates Foundation, through Avahan, its India AIDS Initiative. The views expressed herein are those of the authors and do not necessarily reflect the official policy or position of the Bill \& Melinda Gates Foundation. 